\title{
Activation of cryptic metabolite production through gene disruption: Dimethyl furan-2,4-dicarboxylate produced by Streptomyces sahachiroi
}

\author{
Dinesh Simkhada, Huitu Zhang, Shogo Mori, Howard Williams
}

and Coran M. H. Watanabe*

Letter
Address:
Texas A\&M University, Department of Chemistry, College Station, TX
77843, USA
Email:
Coran M. H. Watanabe* - watanabe@chem.tamu.edu
* Corresponding author
Keywords:
cryptic metabolite; dimethyl furan-2,4-dicarboxylate; genetic knockout;
natural products; non-ribosomal peptide synthetase module;
Streptomyces

\section{Letter}

Address:

Texas A\&M
77843, USA

Email:

Coran M. H. Watanabe* - watanabe@chem.tamu.edu

* Corresponding author

cryptic metabolite; dimethyl furan-2,4-dicarboxylate; genetic knockout; Streptomyces

\author{
Beilstein J. Org. Chem. 2013, 9, 1768-1773. \\ doi:10.3762/bjoc. 9.205 \\ Received: 16 June 2013 \\ Accepted: 09 August 2013 \\ Published: 29 August 2013 \\ This article is part of the Thematic Series "Natural products in synthesis \\ and biosynthesis".
}

Guest Editor: J. S. Dickschat

(C) 2013 Simkhada et al; licensee Beilstein-Institut.

License and terms: see end of document.

\begin{abstract}
At least $65 \%$ of all small molecule drugs on the market today are natural products, however, re-isolation of previously identified and characterized compounds has become a serious impediment to the discovery of new bioactive natural products. Here, genetic knockout of an unusual non-ribosomal peptide synthetase (NRPS) C-PCP-C module, aziA2, is performed resulting in the accumulation of the secondary metabolite, dimethyl furan-2,4-dicarboxylate. The cryptic metabolite represents the first non-azinomycin related compound to be isolated and characterized from the soil bacterium, S. sahachiroi. The results from this study suggest that abolishing production of otherwise predominant natural products through genetic knockout may constitute a means to "activate" the production of novel secondary metabolites that would otherwise lay dormant within microbial genome sequences.
\end{abstract}

\section{Findings}

It has become increasingly apparent that microbial diversity in nature far exceeds that reflected in laboratory strain collections. The advent of microbial genomics and the availability of published genome sequences suggest, that as much as $90 \%$ of the chemical potential of these organisms remain "silent" within the genome $[1,2]$. While the biosynthetic machinery appears functional, the genetic loci are frequently (but not always) unex- pressed. The activation of such pathways has garnered interest from the scientific community. Quorum sensing refers to the process by which microorganisms communicate (within a single bacterial species or between diverse species) and alter their gene expression through production of certain signaling molecules [3]. In this regard, the culturing of microbial communities or the co-culture of two specific microbial organisms has been 
successfully implemented to "activate" secondary metabolite production [4,5]. In some instances, shot-gun cloning and expression of soil samples and bacterial symbiont genomes have led to the discovery of a representative set of natural products and enzymes, albeit typically of small biosynthetic pathways (less than $10 \mathrm{~kb}$ ) [6,7]. Direct manipulation, "induced" biosynthetic activation, of a sequenced cluster has also met with some success. The Aspergillus nidulans genome was mined for cryptic orphan gene clusters from which a single, unexpressed PKS-NRPS hybrid was identified. The expression of the gene cluster was activated by the ectopic expression of a specific regulatory gene, $a p d R$, resulting in the production of the aspyridones [8]. Sometimes, a cryptic pathway is fully expressed and has simply gone unnoticed. In this regard, a genome-isotopic approach has proven useful where stable isotope-labeled putative precursors of the orphan pathway are fed to the organism and used to screen extracts of the fermentation broth, to identify metabolites containing the labeled precursors $[9,10]$.

Here, we have carried out a functional knockout of $a z i A 2$ within the azinomycin gene cluster of Streptomyces sahachiroi $[11,12]$. The gene encodes a NRPS (non-ribosomal peptide synthetase, an enzyme involved in the biosynthesis of various peptide containing secondary metabolites) module of unusual domain architecture consisting of condensation, peptidyl carrier protein, and condensation domains (C-PCP-C), respectively. Gene inactivation led to the abolishment of azinomycin production, confirming the involvement of aziA2 in the biosynthesis of the antitumor agent $[11,13]$ and also led to overproduction of a compound, dimethyl furan-2,4-dicarboxylate. The metabolite represents one of many cryptic pathway metabolites from the $S$. sahachiroi genome and is the first non-azinomycin related compound to be isolated from the S. sahachiroi strain (Figure 1). Previously isolated metabolites consisted of azino- mycin intermediates lacking the 1-azabicyclo[3.1.0] ring system, including naphthoate and naphthoate epoxide derivatives [11].

The aziA2 disruption construct (pKC-AziA2) was generated by replacing the mid-portion (1500 bp) of the gene with a thiostrepton resistance marker within the vector $\mathrm{pKC} 1139$. The plasmid was introduced into $S$. sahachiroi by conjugal transformation. Single crossover mutants were initially selected by culturing the strain on both apramycin and thiostrepton MS-agar plates. The double crossover mutants were subsequently generated from the single crossover mutants by growing the colonies on MS-agar plates in the presence of only thiostrepton antibiotic, resulting in the occurrence of double crossover events. The

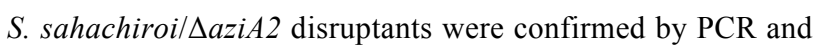
Southern hybridization of thiostrepton resistant and apramycin sensitive colonies. Direct comparison of HPLC profiles of the wild-type and $\triangle a z i A 2$ crude organic extracts were striking (Figure 2). The $\triangle a z i A 2$ mutant gave a single major peak. 3-Methoxy-5-methyl-1-naphthoic acid was detected in trace amounts (suggesting that the metabolite is released in solution from the PKS and not directly transferred to that of a subsequent NRPS module) and complete abolishment of the azinomycins was observed. The production of the naphthoic acid derivative and lack of azinomycin production confirms the involvement of aziA2 (C-PCP-C NRPS module) in azinomycin biosynthesis; given the unique domain architecture of this module, this is a significant finding as non-functional NRPS modules have been found imbedded in certain gene clusters [14].

Structural characterization of the major metabolite was carried out using LC-MS analysis and 1D and 2D cryoprobe NMR spectroscopy (data provided in Supporting Information File 1).

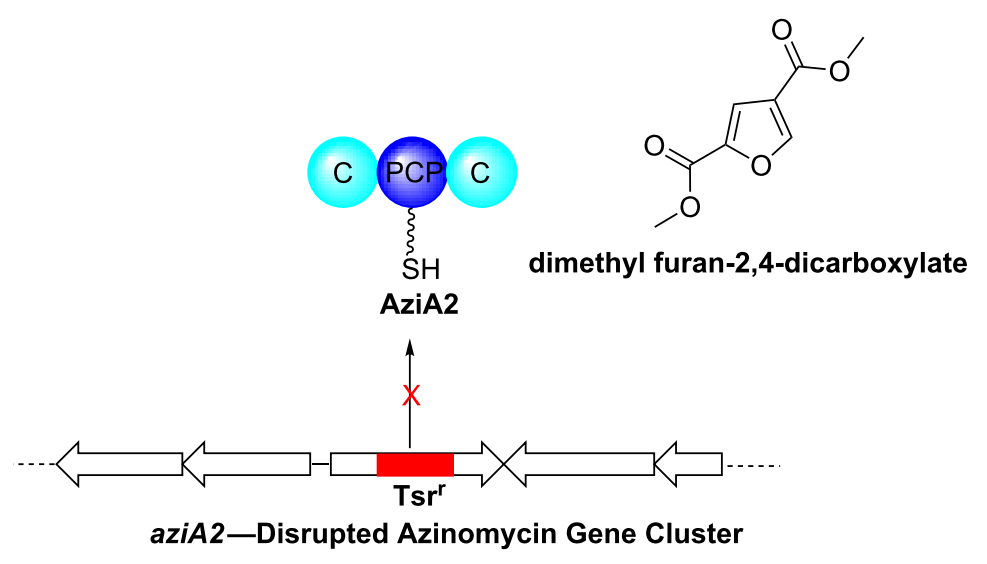

Figure 1: Schematic diagram illustrating the phenotypic effects arising through deletion of the aziA2 gene. 

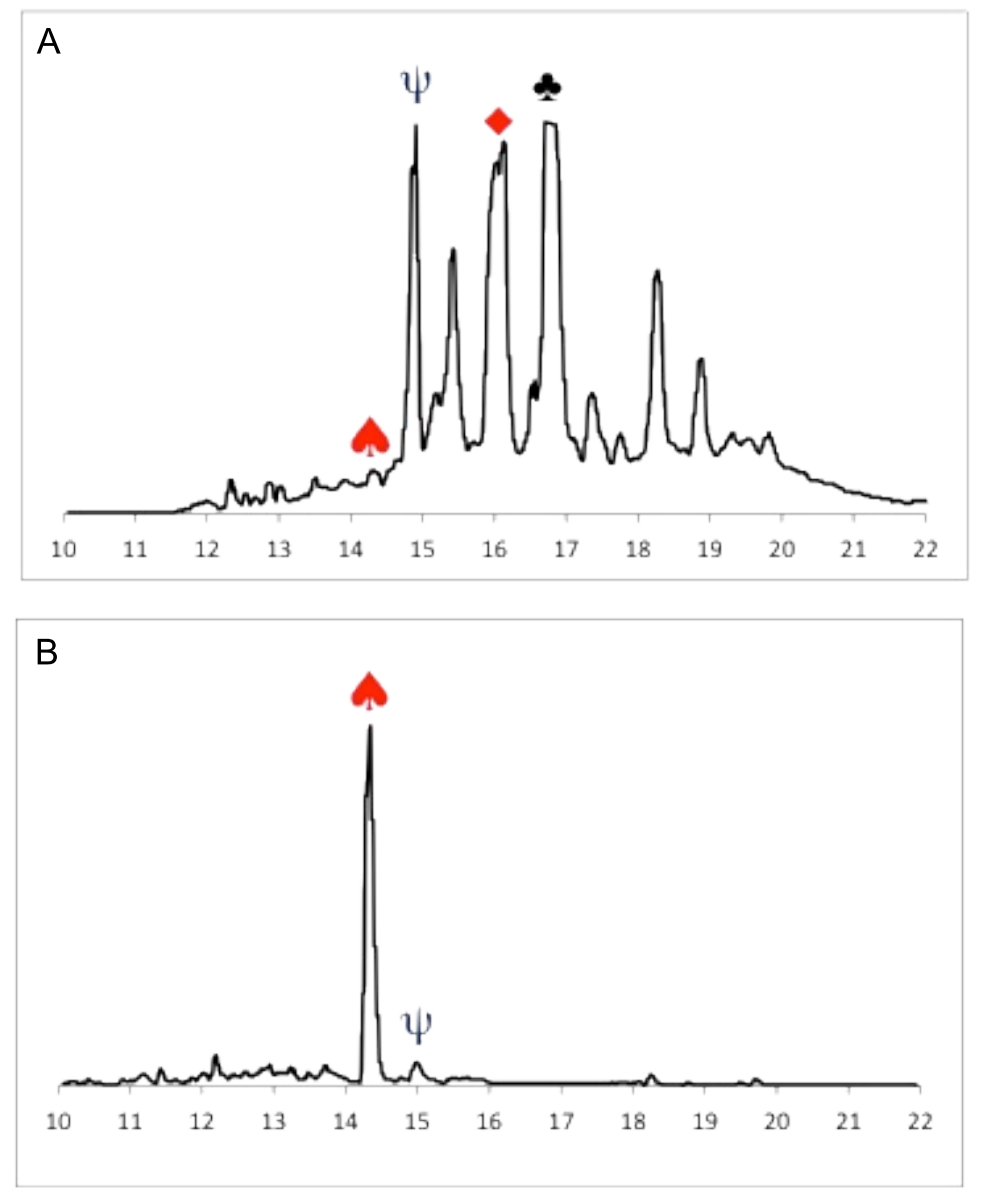

dimethyl furan-2,4-dicarboxylate $\psi$ 3-methoxy-5-methyl-1-naphthoic acid

azinomycin $\mathrm{A}$ azinomycin B<smiles>COc1cc(C(=O)O)c2cccc(C)c2c1</smiles>

3-methoxy-5-methyl-1naphthoic acid

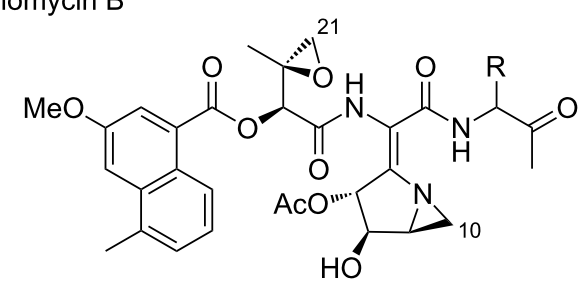

azinomycin $\mathrm{A}, \mathrm{R}=\mathrm{H}_{2}$

azinomycin $\mathrm{B}, \mathrm{R}=\xi \hat{\mathrm{OH}}$

Figure 2: HPLC profiles of (A) S. sahachiroi wild-type and (B) $\triangle a z i A 2$ crude organic extracts.

The molecular formula was established as $\mathrm{C}_{8} \mathrm{H}_{8} \mathrm{O}_{5}$ based upon a molecular ion peak observed by LC-APCIMS at $\mathrm{m} / \mathrm{z}$ 185.0453 [M + H $]^{+}$and GC-MS. The GC-MS fragmentation of the compound matched that provided in the Ultra GC-DSQ (ThermoElectron, Waltham, MA) GC-MS database. The structure of the compound was determined by NMR analysis in $\mathrm{CDCl}_{3}$ (Table 1). The presence of two $\mathrm{O}-\mathrm{CH}_{3}$ groups at $\mathrm{C}-2$, $\left(\delta_{\mathrm{c}} 51.99, \delta_{\mathrm{H}} 3.94\right)$ and $\mathrm{C}-2 "\left(\delta_{\mathrm{c}} 52.31, \delta_{\mathrm{H}} 3.88\right)$ and double bonds in the aromatic ring at $\mathrm{C}-3\left(\delta_{\mathrm{c}} 117.07, \delta_{\mathrm{H}} 7.49, \mathrm{~d}\right.$, $J=0.811)$ and $\mathrm{C} 5\left(\delta_{\mathrm{c}} 150.14 \delta_{\mathrm{H}} 8.14, \mathrm{~d}, J=0.845\right)$ were observed by ${ }^{1} \mathrm{H}$ NMR, DEPT, HMQC and HMBC. C-1" $\left(\delta_{\mathrm{c}}\right.$ $158.53), \mathrm{C}-2\left(\delta_{\mathrm{c}} 145.44\right), \mathrm{C}-5\left(\delta_{\mathrm{c}} 150.14\right)$ and $\mathrm{C}-1$ ' $\left(\delta_{\mathrm{c}} 162.34\right)$ signals were detected by ${ }^{13} \mathrm{C}$ NMR (Table 1$)$. The data identified the compound as dimethyl furan-2,4-dicarboxylate, which 
has been previously observed in microbial head-space or vapor phase extracts and its structure determined through chemical synthesis [15]. The biosynthetic origin of dimethyl furan-2,4dicarboxylate could be polyketide derived where the furan ring system could be envisioned to form through nucleophilic attack of an epoxide as in the case with monensin and other similar natural products [16]. Alternatively, the biosynthesis might involve the dimerization of pyruvate [17-19]. Examination of a draft genome sequence of the $S$. sahachiroi strain has implicated a pyruvate aldolase and methyltransferase containing gene cluster as well as potential polyketide gene clusters containing methyltransferase genes, which will be evaluated in due course through genetic knockout experiments of the $\triangle a z i A 2$ mutant strain.

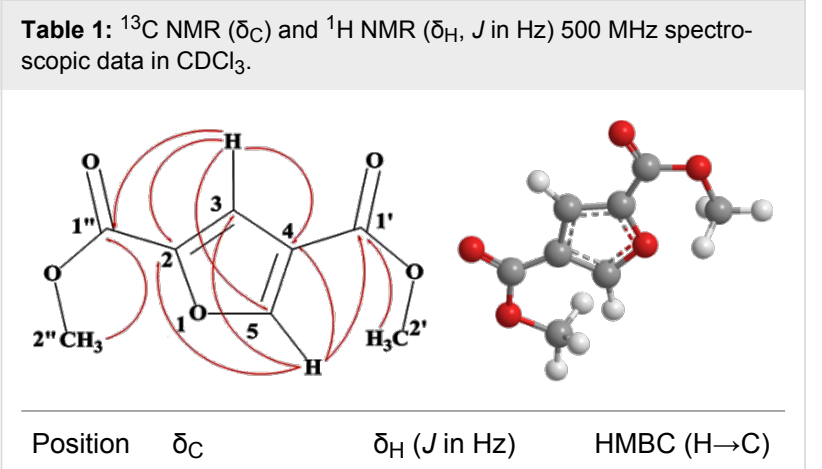

1 2 3 4 5 1 $1 "$ 2 $2 "$
Disruption of the aziA2 gene gave overproduction of the cryptic metabolite dimethyl furan-2,4-dicarboxylate and led to complete abolishment of azinomycin production. It is the first non-azinomycin related metabolite to be reported from the S. sahachiroi strain, a microorganism that has been mined for its natural product constituents since 1954 [20]. These results demonstrate that while some disruption strains will certainly be more easily characterized than others, the act of simply inactivating genes from highly expressed or represented biosynthetic gene clusters can be a useful strategy toward revealing or unmasking novel natural products or cryptic metabolites for subsequent isolation and characterization. Secondary metabolite production by microorganisms is often viewed as a line of defense against competing microbes for nutrients. Natural prod- ucts like azinomycin, a DNA crosslinking agent, can offer a means of protection to the producing organism. It is tempting to speculate that when biosynthetic pathways of these metabolites are inactivated, the microorganism begins to adapt and evolve in an effort to develop new self defense mechanisms. Such adaptations (which may or may not be immediately useful to the host) can lead to the production of new metabolites such as dimethyl furan-2,4-dicarboxylate.

\section{Experimental \\ DNA manipulation and methods}

Conventional recombinant DNA techniques were utilized for plasmid and genomic DNA isolation, restriction enzyme digestion, agarose gel electrophoresis, and DNA ligations [21]. DNA sequencing was performed using ABI BigDye chemistry at the Gene Technologies Lab, Texas A\&M University. The computer-based analysis and comparisons of nucleotide and protein sequences were performed with BLAST, FASTA, CLUSTALW and GENEDOC programs. See Supporting Information File 1 for details on bacterial strains, plasmids, PCR primer sequences, and bacterial culture conditions.

\section{Construction of disruption plasmid pKCAziA2}

Disruption of aziA2 was performed using a homologous recombination approach with pKC1139. PCR with primer pairs aziA2UF/aziA2UR and aziA2DF/aziA2DR was utilized to generate a 930 bp upstream fragment and 923 bp downstream fragment relative to $a z i A 2$. Amplification was carried out as follows: initial denaturation at $98^{\circ} \mathrm{C}$ for $30 \mathrm{~s} ; 30$ total cycles of denaturation for $10 \mathrm{~s}$; annealing at $66.4{ }^{\circ} \mathrm{C}$ for aziA2UF/ aziA2UR and $62{ }^{\circ} \mathrm{C}$ for aziA2DF/aziA2DR for $40 \mathrm{~s}$; polymerization at $72{ }^{\circ} \mathrm{C}$ for $60 \mathrm{~s}$ and finally gap filing at $72{ }^{\circ} \mathrm{C}$ for $10 \mathrm{~min}$. The amplified DNA fragment of azia2-U was digested with HindIII/XbaI (azia2-U) and XbaI/EcoRI (azia2-D) and cloned into the corresponding sites of $\mathrm{pKC} 1139$, resulting in pKCA2UD. pKCA2UD was digested with $\mathrm{XbaI}$ and ligated with the thiostrepton-resistance gene (1056 bp), which was amplified with $\mathrm{TsrF} / \mathrm{TsrR}$ primers using the same amplification condition as detailed for aziA2DF/aziA2DR, to give the final disruption recombinant plasmid pKC-AziA2, where aziA2 is replaced by $\operatorname{tsr}^{\mathrm{r}}$ in-frame.

\section{Conjugal transformation with plasmid pKCAziA2}

pKC-AziA2 was transformed into E. coli $\mathrm{S}-17$, a donor host and subsequently transferred into wild type, S. sahachiroi by conjugal transformation, as described by Kieser et al. (with some modification) [22] for deletion with a replicative plasmid as mediated by homologous recombination. From an overnight $5 \mathrm{~mL}$ culture of $E$. coli donor strain, $100 \mu \mathrm{L}$ was transferred into $100 \mathrm{~mL}$ fresh LB medium and cultured for $4 \mathrm{~h}$. The cells at 
OD600 0.6 were harvested, washed twice and solubilized in $500 \mu \mathrm{L}$ of $2 \mathrm{xYT}$ medium. Spores of S. sahachiroi were prepared in MS agar plates and collected after one week. Spores were washed, heat shocked at $70{ }^{\circ} \mathrm{C}$ for $10 \mathrm{~min}$ and incubated at $37^{\circ} \mathrm{C}$ for $4 \mathrm{~h}$. Following incubation, they were washed and resuspended in $500 \mu \mathrm{L}$ of $2 x Y T$ medium. These recipient cells were mixed with an equal volume of $E$. coli donor cells and $200 \mu \mathrm{L}$ of the mixture were plated on MS-agar plates. The plates were incubated at $30{ }^{\circ} \mathrm{C}$ for $18 \mathrm{~h}$, and overlayed with $1 \mathrm{~mL}$ water containing nalidixic acid $(500 \mu \mathrm{g})$, to inhibit the growth of E. coli, and apramycin $(25 \mu \mathrm{g})$ to select $S$. sahachiroi exconjugants. Incubation at $30{ }^{\circ} \mathrm{C}$ was continued for $6-8$ days to allow growth of the exconjugants. Apramycin exconjugants were screened for several generations until the exconjugants were found to be apramycin sensitive and thiostrepton resistant to detect the double crossover allelic exchange. For further confirmation of deletion of aziA2 from S. sahachiroi, genomic DNA was isolated from both $S$. sahachiroi wild-type and aziA2

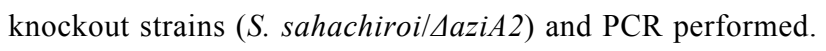
The AziA2UF/TsrR and TsrF/AziA2DR primer set was utilized: initial denaturation at $98{ }^{\circ} \mathrm{C}$ for $30 \mathrm{~s} ; 30$ total cycles of denaturation for $10 \mathrm{~s}$; annealing at $64.5^{\circ} \mathrm{C}$ for $40 \mathrm{~s}$; polymerization at $72{ }^{\circ} \mathrm{C}$ for $60 \mathrm{~s}$ and finally gap filing at $72{ }^{\circ} \mathrm{C}$ for $10 \mathrm{~min}$. Southern hybridization was carried out following standard procedures [21] with a radioactive ${ }^{32} \mathrm{P}$-ATP labeled probe. The probe was generated through PCR amplification using the aziA2 probe-F/aziA2 Probe R set of primers and following the same PCR condition as detailed above.

\section{Fermentation and analysis of secondary metabolites}

Fermentation was carried out in $10 \mathrm{~L}$ following established procedures [23]. After $72 \mathrm{~h}$ of incubation, the culture broth was centrifuged and the supernatant extracted with dichloromethane ( $2 \times$ the volume of the medium). The organics were concentrated in vacuo and analyzed by reversed-phase HPLC. The column, Phenomenex, Columbus $5 \mu$ C8 100A $(250 \times 3.20 \mathrm{~mm}$ $5 \mu)$ was equilibrated with $10 \%$ of $\mathrm{A}(75 \% \mathrm{MeOH} / 25 \%$ isopropanol) and $90 \%$ of $\mathrm{B}$ (water) and run with the following program: Time 0 min A-10\%; 1 min A-10\%; 5 min A-35\%; 14 min A-95\%; 15 min A-95\%; 20 min A-10\%; 25 min A-10\%; $60 \mathrm{~min} \mathrm{~A}-100 \%$. This was carried out at a flow rate of $0.75 \mathrm{~mL} / \mathrm{min}$ in $254 \mathrm{~nm} \mathrm{UV}$. The same program was used for LC-APCI analysis. For GC-MS analysis, the sample was diluted 1:10 in DCM and was performed on an Ultra GC/DSQ (ThermoElectron, Waltham, MA). A Rxi-5ms gas chromatographic column was utilized with dimensions of $60 \mathrm{~m}$ length, $0.25 \mathrm{~mm}$ i.d., and $0.25 \mu \mathrm{m}$ film thickness (Restek; Bellefonte, PA). Helium was implemented as a carrier gas at a constant flow rate of $1.5 \mathrm{~mL} / \mathrm{min}$. The transfer line and ion source were held at $250{ }^{\circ} \mathrm{C}$. The column temperature was maintained at
$50{ }^{\circ} \mathrm{C}$ for $5 \mathrm{~min}$ then raised to $320{ }^{\circ} \mathrm{C}$ for $20^{\circ} \mathrm{C} / \mathrm{min}$. Mass spectra were acquired in full scan mode in the range of $30-500 \mathrm{~m} / \mathrm{z}$.

\section{Cryoprobe NMR analysis}

NMR spectra were acquired on a Bruker Avance III $500 \mathrm{MHz}$ instrument at $25^{\circ} \mathrm{C}$, equipped with a $5 \mathrm{~mm} \mathrm{H}-\mathrm{C}-\mathrm{N}$ cryoprobe. The sample was dissolved in $125 \mu \mathrm{L} \mathrm{CDCl}_{3}$ and contained in a $3 \mathrm{~mm}$ wilmad 335 pp NMR tube. Proton, carbon, Dept 90, Dept 135, HMQC and HMBC spectra were recorded. A $30^{\circ}$ observe pulse was used to acquire the ${ }^{1} \mathrm{H}$ NMR spectrum, while a $45^{\circ}$ pulse was used to obtain the ${ }^{13} \mathrm{C}$ NMR spectrum.

\section{Supporting Information}

\section{Supporting Information File 1}

Details on genetic knockout, Southern blot analysis,

LC-MS analysis and NMR data.

[http://www.beilstein-journals.org/bjoc/content/

supplementary/1860-5397-9-205-S1.pdf]

\section{Acknowledgements}

The authors are indebted to the American Cancer Society and the Welch Foundation (Grant \#A-1828) for financial support of this work.

\section{References}

1. Bentley, S. D.; Chater, K. F.; Cerdeño-Tárraga, A.-M.; Challis, G. L.; Thomson, N. R.; James, K. D.; Harris, D. E.; Quail, M. A.; Kieser, H.; Harper, D.; Bateman, A.; Brown, S.; Chandra, G.; Chen, C. W.; Collins, M.; Cronin, A.; Fraser, A.; Goble, A.; Hidalgo, J.; Hornsby, T.; Howarth, S.; Huang, C.-H.; Kieser, T.; Larke, L.; Murphy, L.; Oliver, K.; O'Neil, S.; Rabbinowitsch, E.; Rajandream, M.-A.; Rutherford, K.; Rutter, S.; Seeger, K.; Saunders, D.; Sharp, S.; Squares, R.; Squares, S.; Taylor, K.; Warren, T.; Wietzorrek, A.; Woodward, J.; Barrell, B. G.; Parkhill, J.; Hopwood, D. A. Nature 2002, 417, 141-147. doi:10.1038/417141a

2. Oliynyk, M.; Samborskyy, M.; Lester, J. B.; Mironenko, T.; Scott, N.; Dickens, S.; Haydock, S. F.; Leadlay, P. F. Nat. Biotechnol. 2007, 25, 447-453. doi:10.1038/nbt1297

3. Reading, N. C.; Sperandio, V. FEMS Microbiol. Lett. 2006, 254, 1-11. doi:10.1111/j.1574-6968.2005.00001.x

4. Angell, S.; Bench, B. J.; Williams, H.; Watanabe, C. M. H. Chem. Biol. 2006, 13, 1349-1359. doi:10.1016/j.chembiol.2006.10.012

5. Oh, D.-C.; Kauffman, C. A.; Jensen, P. R.; Fenical, W. J. Nat. Prod. 2007, 70, 515-520. doi:10.1021/np060381f

6. Brady, S. F.; Chao, C. J.; Clardy, J. J. Am. Chem. Soc. 2002, 124, 9968-9969. doi:10.1021/ja0268985

7. Courtois, S.; Cappellano, C. M.; Ball, M.; Francou, F.-X.; Normand, P.; Helynck, G.; Martinez, A.; Kolvek, S. J.; Hopke, J.; Osburne, M. S.; August, P. R.; Nalin, R.; Guérineau, M.; Jeannin, P.; Simonet, P.; Pernodet, J.-L. Appl. Environ. Microbiol. 2003, 69, 49-55. doi:10.1128/AEM.69.1.49-55.2003 
8. Bergmann, S.; Schümann, J.; Scherlach, K.; Lange, C.; Brakhage, A. A.; Hertweck, C. Nat. Chem. Biol. 2007, 3, 213-217. doi:10.1038/nchembio869

9. Challis, G. L. Microbiology 2008, 154, 1555-1569. doi:10.1099/mic.0.2008/018523-0

10. Gross, H. Appl. Microbiol. Biotechnol. 2007, 75, 267-277. doi:10.1007/s00253-007-0900-5

11. Foulke-Abel, J.; Agbo, H.; Zhang, H.; Mori, S.; Watanabe, C. M. H. Nat. Prod. Rep. 2011, 28, 693-704. doi:10.1039/c0np00049c

12. Zhao, Q.; He, Q.; Ding, W.; Tang, M.; Kang, Q.; Yu, Y.; Deng, W.; Zhang, Q.; Fang, J.; Tang, G.; Liu, W. Chem. Biol. 2008, 15, 693-705. doi:10.1016/j.chembiol.2008.05.021

13. Kelly, G. T.; Liu, C.; Smith, R., III; Coleman, R. S.; Watanabe, C. M. H. Chem. Biol. 2006, 13, 485-492. doi:10.1016/j.chembiol.2006.02.015

14. Finking, R.; Marahiel, M. A. Annu. Rev. Microbiol. 2004, 58, 453-488. doi:10.1146/annurev.micro.58.030603.123615

15. Citron, C. A.; Rabe, P.; Dickschat, J. S. J. Nat. Prod. 2012, 75 , 1765-1776. doi:10.1021/np300468h

16. Oliynyk, M.; Stark, C. B. W.; Bhatt, A.; Jones, M. A.; Hughes-Thomas, Z. A.; Wilkinson, C.; Oliynyk, Z.; Demydchuk, Y.; Staunton, J.; Leadlay, P. F. Mol. Microbiol. 2003, 49, 1179-1190. doi:10.1046/j.1365-2958.2003.03571.x

17. Wang, W.; Mazurkewich, S.; Kimber, M. S.; Seah, S. Y. K. J. Biol. Chem. 2010, 285, 36608-36615. doi:10.1074/jbc.M110.159509

18. Hara, H.; Masai, E.; Miyauchi, K.; Katayama, Y.; Fukuda, M. J. Bacteriol. 2003, 185, 41-50. doi:10.1128/JB.185.1.41-50.2003

19. Maruyama, K.; Miwa, M.; Tsujii, N.; Nagai, T.; Tomita, N.; Harada, T.; Sobajima, H.; Sugisaka, H. Biosci., Biotechnol., Biochem. 2001, 65, 2701-2709. doi:10.1271/bbb.65.2701

20. Hata, T.; Koga, F.; Sano, Y.; Kanamori, K.; Matsumae, A.; Sugawara, R.; Hoshi, T.; Shima, T.; Ito, S.; Tomizawa, S. J. Antibiot., Ser. A 1954, 7, 107-112.

21. Sambrook, J. R.; Russell, D. W. Molecular Cloning a Laboratory Manual; Cold Spring Harbour Laboratory Press: Cold Spring Harbour, 2001; 6.33-6.38.

22. Kieser, T.; Bibb, M. J.; Buttner, M. J.; Chater, K. F.; Hopwood, D. A. Practical Streptomyces Genetics; The John Innes Foundation: Norwich, UK, 2000.

23. Kelly, G. T.; Sharma, V.; Watanabe, C. M. H. Bioorg. Chem. 2008, 36, 4-15. doi:10.1016/j.bioorg.2007.08.002

\section{License and Terms}

This is an Open Access article under the terms of the Creative Commons Attribution License (http://creativecommons.org/licenses/by/2.0), which permits unrestricted use, distribution, and reproduction in any medium, provided the original work is properly cited.

The license is subject to the Beilstein Journal of Organic Chemistry terms and conditions: (http://www.beilstein-journals.org/bjoc)

The definitive version of this article is the electronic one which can be found at: doi:10.3762/bjoc. 9.205 